Didáctica. Lengua y literatura

ISSN-e: 1988-2548

https://dx.doi.org/10.5209/dida.65949

\title{
Sobre la aproximación a la obra dramática de Calderón de la Barca en la Educación Secundaria: del currículo al libro de texto
}

\author{
Alejandra Ulla Lorenzo ${ }^{1}$
}

Fecha revisión: 04-02-2018 / Fecha aceptación: 28-05-2019

Resumen. El objetivo del presente artículo consiste en proponer una aproximación crítica a la perspectiva desde la cual se estudia la obra del dramaturgo Calderón de la Barca en la Educación Secundaria. Para ello partiremos de las indicaciones que nos ofrece el currículo estatal, publicado en el Real Decreto 1105/2014 por el que se establece el currículo básico de la Educación Secundaria Obligatoria y del Bachillerato, a través de los contenidos de la materia Lengua Castellana y Literatura. Desde este punto examinaremos un corpus de veinticinco libros de texto de diferentes editoriales españolas publicados entre 2015 y 2016, con la finalidad de analizar cómo se enfoca el proceso de enseñanza-aprendizaje de la obra de este autor en el primer ciclo de la ESO y en el primer curso de Bachillerato, la etapa y curso a las que se asocia la didáctica de la literatura española del Siglo de Oro.

Palabras clave: Calderón de la Barca, Educación Secundaria, currículum, libro de texto.

\section{[en] On the Approach to Calderón de la Barca's Dramatic Work in Secondary Education: From Curriculum to Textbook}

\begin{abstract}
The aim of the present article consists in proposing a critical approximation to the perspective from which the work of the dramatist Calderón de la Barca has been studied in the Secondary Education. For this will split of the indications that offers us the state curriculum, published in the Real Decreto 1105/2014 por el que se establece el currículo básico de la Educación Secundaria Obligatoria y del Bachillerato, through the contents of the subject Spanish Language and Literature. From this point we will examine a corpus of twenty-five textbooks of different Spanish publishers published between 2015 and 2016 with the purpose to analyse how focuses the process of education-learning of the work of this author in the first cycle of the ESO and in the first course of Bachillerato, the stage and course to which associates the didactic of the Spanish Golden Age literature.
\end{abstract}

Keywords: Calderón de la Barca, Secondary Education, curriculum, textbook.

\section{[fr] Sur l'approche du travail dramatique de Calderón de la Barca dans l'enseignement secondaire : du programme au manuel scolaire}

Résumé. L'objectif du présent article consiste à proposer une approximation critique à la perspective depuis laquelle s'étudie l'oeuvre du dramaturgo Calderón de la Barque dans l'Éducation Secondaire. Pour cela nous partirons des indications qu'il nous offre le currículo de l'État, publié dans le Real Decreto 1105/2014 por el que se establece el currículo básico de la Educación Secundaria

\footnotetext{
$1 \quad$ Universidad Internacional de La Rioja alejandra.ulla@unir.net
} 
Obligatoria y del Bachillerato, à travers les contenus de la matière Langue Castillane et Littérature. Depuis ce point nous examinerons un corpus de vingt-cinq livres de texte de différents éditoriaux espagnoles publiés entre 2015 et 2016 avec la finalité d'analyser comment se dirige le procès d'enseignement-apprentissage de l'oeuvre de cet auteur dans le premier cycle de la ESO et dans le premier cours de Bachillerato, l'étape et cours à celles que s'associe la didáctica de la littérature spagnole du Siècle d'Or.

Mots-clés: Calderón de la Barca, Éducation Secondaire, curriculum manuel scolaire.

Sumario. 1. Introducción: El currículum, el libro de texto y el aula. 2. Calderón ayer y hoy: del currículum al libro de texto del primer ciclo de la ESO. 3. Calderón ayer y hoy: del currículum al libro de texto del primer curso de Bachillerato. 4. Ilustraciones para acompañar el estudio de la obra de Calderón en los manuales del primer ciclo de la ESO y el primer curso de Bachillerato. 5. Conclusiones. 6. Bibliografía. 7. Corpus de libros de texto

Cómo citar: Ulla Lorenzo, A. (2019). Sobre la aproximación a la obra dramática de Calderón de la Barca en la Educación Secundaria: del currículo al libro de texto, Didáctica. Lengua y literatura, 31, 217-231.

\section{Introducción: el currículum, el libro de texto y el aula}

E1 Real Decreto 1105/2014, de 26 de diciembre, por el que se establece el currículo básico de la Educación Secundaria Obligatoria y del Bachillerato, indica que la distribución de los contenidos de historia de la literatura española durante la ESO y el Bachillerato ha de ser progresiva y que, por tanto, debe partir de un estudio de los géneros literarios para luego estudiar cada etapa y, finalmente, profundizar en la obra y su contexto siempre a través del trabajo con textos relevantes:

La distribución de contenidos se reparte a lo largo de las etapas de la siguiente manera. En la ESO se aborda un estudio progresivo de la literatura: se parte de un acercamiento a los géneros literarios y se continúa planteando progresivamente una visión cronológica desde la Edad Media hasta el siglo XX, siempre a través de la selección de textos significativos. Será en los dos cursos del Bachillerato cuando el alumnado profundice en la relación entre el contexto sociocultural y la obra literaria (Real Decreto 1105/2014, 2015, 359).

Si nos centramos en el primer ciclo de la ESO de la asignatura Lengua Castellana y Literatura concretamente en el Bloque 4, Educación literaria, el currículum menciona, como contenido, la "aproximación a los géneros literarios y a las obras más representativas de la literatura española de la Edad Media al Siglo de Oro a través de la lectura y explicación de fragmentos significativos y, en su caso, textos completos" (Real Decreto 1105/2014, 2015, 364), lo que refuerza la idea antes mencionada de la importancia del trabajo con los textos para explicar los géneros literarios y la literatura medieval y áurea.

Por su parte, en lo que se refiere al primer curso de Bachillerato, de nuevo en el Bloque 4, Educación literaria, se recogen como contenidos el estudio de obras concretas pertenecientes al período que comprende desde la Edad Media al siglo XX a través de fragmentos u obras completas: 
- Estudio de las obras más representativas de la literatura española desde la Edad Media hasta el siglo XIX, a través de la lectura y análisis de fragmentos y obras significativas.

- Análisis de fragmentos u obras completas significativas desde la Edad Media al siglo XIX, identificando sus características temáticas y formales relacionándolas con el contexto, el movimiento, el género al que pertenece y la obra del autor y constatando la evolución histórica de temas y formas.

- Interpretación crítica de fragmentos u obras significativas desde la Edad Media al siglo XlX, detectando las ideas que manifiestan la relación de la obra con su contexto histórico, artístico y cultural.

- Planificación y elaboración de trabajos académicos escritos o presentaciones sobre la literatura desde la Edad Media hasta el siglo XIX, obteniendo la información de fuentes diversas y aportando un juicio crítico personal y argumentado con rigor. (Real Decreto 1105/2014, 2015, 374).

Por tanto, del currículum podemos inferir el estudio de la literatura española del siglo XVII y, asimismo, de su teatro, en los tres primeros cursos de la ESO y, también, en el primero de Bachillerato, aunque el texto no precisa ni los autores ni sus obras o su distribución. Serán los libros de texto los que interpreten dichas indicaciones y concreten los contenidos curriculares en cursos específicos. En este sentido parece interesante recordar las palabras de Escolano, quien se refiere al libro de texto como "un soporte curricular, a través del cual se vehicula la vulgata escolar, o sea, el conocimiento academizado que las instituciones educativas han de transmitir" (Escolano, 2009, 172).

El mismo autor ha reflexionado, también, sobre cómo el manual escolar es, asimismo, un reflejo de la sociedad en la que se elabora, lo que supone, que sus contenidos sean acordes a ese contexto:

De otra parte, el libro escolar es un espacio de memoria como espejo de la sociedad que lo produce, en cuanto en él se representan valores, actitudes, estereotipos e ideologías que caracterizan la mentalidad dominante, de una determinada época, o lo que es lo mismo, el imaginario colectivo que configura algunos aspectos fundamentales de lo que hoy se entiende por currículum oculto, y también del explícito (Escolano, 2009, 172).

Son muchos los trabajos en los que, a lo largo de los últimos años, se ha discutido sobre la pertinencia o no del libro en las aulas (San Martín Alonso y Peirats Chacón, 2017). El primer grupo, además, se ha ocupado en un número muy extenso de publicaciones planteadas diacrónica o sincrónicamente, entre las cuales citamos los más recientes, del análisis de los contenidos de los libros de texto de diferentes disciplinas académicas como las Matemáticas (Martín Martín, 2017), la Química (González Felipe, Aguirre Pérez, Cortés Simarro, Fernández Cezar, Vázquez Molini, 2017), la Historia (Gómez Carrasco y Rodríguez Pérez, 2017), la Música (Peréz, 2017), la Dialectología (López García, 2017), la Ortografía (Ayala Ato y Montaner Bueno, 2017), la enseñanza de español como lengua extranjera (Arboleda González, 2017) o la historia de la literatura (Sánchez Dueñas, 2012). Dichas investigaciones surgen con el objetivo de estudiar cómo se concretan en las mencionadas herramientas los contenidos que las instituciones estatales y autonómicas transmiten. Entre todas las 
asignaturas trabajadas hasta el momento, la más tratada ha sido, sin duda, la Historia. A este respecto en un trabajo del 2014, Gómez, Cózar y Miralles indicaban cómo esta línea de investigación se había convertido en "fundamental para comprender las tensiones en la enseñanza de la historia, su problemática y relaciones con el poder, los currículos y el contexto histórico, social y cultural" (16). Estas palabras podrían fácilmente trasladarse al ámbito de la historia de la literatura $\mathrm{y}$, sin embargo, no es una disciplina en la que hayan florecido muchos trabajos en esta línea. Entre ellos merece la pena recordar el antes citado de Sánchez Dueñas (2012), por cuanto se refiere particularmente a la introducción de la perspectiva de género en la enseñanza de la literatura aurisecular, un tema que también se trata en la guía de Heredero de Pedro (2013).

Muy otra es la situación si atendemos a la investigación sobre la didáctica de la literatura y, más concretamente, del teatro del Siglo de Oro, en el aula de Secundaria ${ }^{2}$, es decir, la aplicación práctica de los contenidos que marca en currículum y concreta el libro de texto. En este sentido han de recordarse los artículos de Ontanaya Pastrana (2004), Pérez Fernández (2011) y Vila Carneiro (2017), así como las tesis doctorales de Pérez Fernández (2009) y de Udaondo Alegre (2008).

Por todos los motivos anteriormente expuestos, nos ha parecido interesante examinar el modo en que Calderón de la Barca se presenta en una selección significativa de libros de texto, a través de los cuales hemos analizado qué tipo de valores, estereotipos o ideología subyacen en el enfoque que se le otorga a su obra.

Para alcanzar nuestro objetivo hemos escogido entre cinco y siete manuales de diferentes editoriales pertenecientes a cada uno de los cursos que nos interesan en la presente investigación: $1^{\circ}, 2^{\circ}, 3^{\circ}$ de la ESO y $1^{\circ}$ de Bachillerato. Este número de libros nos permite obtener un abanico amplio de informaciones. Posteriormente, hemos procedido a su análisis a través de cuatro parámetros: el género y subgéneros dramáticos mencionados, el corpus de obras calderonianas seleccionado, los textos que se citan y las ilustraciones que se observan en los manuales ${ }^{3}$.

\section{Calderón ayer y hoy: del currículum al libro de texto del primer ciclo de la ESO}

En lo que se refiere a los resultados que arroja el análisis de los siete manuales escolares de $1^{\circ}$ de la ESO, es importante indicar cómo todos ellos presentan una aproximación a los tres géneros literarios primarios: prosa, poesía y teatro. En el contexto de este último se distingue: tragedia, comedia y drama, subgénero al que se asocia la figura de Calderón al menos en uno de los manuales (Pantoja Rivero et alii, 2015, 210). Asimismo, en los siete libros encontramos fragmentos de obras dramáticas a partir de los cuales se ejemplifican las diferentes características de los textos teatrales. De esta forma se cumple con lo que marca el currículum. Parece relevante indicar, no obstante, cómo solo en uno de ellos, el de la editorial Edelvives

2 También ha de mencionarse un trabajo dedicado al teatro áureo como parte de la educación literaria de la etapa de Primaria (Cienfuegos Antelo, 2016) y otro a la etapa de Infantil (Vara López y Vila Carneiro, 2017 y los referidos la enseñanza del teatro en el aula de español (Sainz García, 2014; Vila Carneiro, 2015; Palacios González, 2017).

3 Al final de este artículo se incluye, a continuación del apartado de bibliografía, el corpus de los manuales que manejamos. 
(Jiménez Pérez, 2015, 103), se ha escogido como texto uno de Calderón de la Barca que, concretamente, pertenece al monólogo de Segismundo de La vida es sueño y se emplea para ejemplificar el monólogo y el diálogo. Por tanto, en los libros analizados Calderón no se trata como contenido sino como ejemplo de un género o como texto literario modelo. En cuanto al texto debe indicarse que este se extrae, no por casualidad, de una edición de la obra escolar publicada por la misma editorial que imprime el manual.

Si atendemos ahora a los siete manuales de $2^{\circ}$ de la ESO seleccionados observamos cómo en general, se profundiza en los géneros literarios y se tratan también diferentes subgéneros; además encontramos un mayor número de referencias al teatro del Siglo de Oro y, concretamente, a Calderón de la Barca que en los del curso anterior. Así, dos manuales (Moreno et alii, 2016, 237 y Garrido González, 2016, 318 ) ofrecen apartados, aunque muy superficiales, en los que se menciona al dramaturgo. El segundo aporta, junto con el manual de Vicens Vivens (Escribano Alemán y Rodríguez Delgado, 2016, 252), un fragmento de La vida es sueño, concretamente el monólogo de Segismundo, como ejemplo de drama filosófico, y de El alcalde de Zalamea, como ejemplo de drama de honor, esta vez citados por ediciones de Austral que, si bien son escolares, sí han seguido los criterios propios de la ecdótica y presentan textos fiables.

En el conjunto de los libros de $2^{\circ}$ de la ESO ha llamado nuestra atención el de Edebé (Garrido González, 2016), pues contiene, al final del cuaderno del tercer trimestre, un monográfico sobre literatura barroca en el que se dedica un bloque completo al teatro. Este está integrado por una introducción (316) y dos apartados, uno dedicado a Lope de Vega (316) y otro a Calderón (317). Ambos aparecen mencionados en la introducción: el primero como precursor y el segundo en tanto que máximo representante de la "comedia nacional". Parece importante detenerse en esta etiqueta empleada para hacer referencia a la nueva forma de hacer teatro que Lope inaugura y explica en su Arte nuevo de hacer comedias (1609), es decir, a la "comedia nueva".

El rótulo "comedia nacional" proviene de las historias de la literatura románticas, como muy bien ha explicado Martín Ezpeleta, momento en el que el teatro cobra un extraordinario protagonismo y, particularmente, la figura Lope de Vega, pues se entiende que su producción dramática "no solo nace de su inteligencia artística, sino del esplendor sociopolítico de la época" $(2008,451)$. Importa considerar que la etiqueta supone:

una convención intelectual cuya probada utilidad a la hora de iniciar los estudios de literatura no ha llegado a rivalizar con ninguna otra. Y es que no hay que olvidar que las instituciones del pasado no perseguían profundizar en el análisis literario, sino formar culturalmente (a) la nación. Esto es, educar y estimular la sensibilidad literaria de los alumnos en las aulas, a la vez que se preparaba la cara artística del prisma Estado-nación que estaba confirmándose a raíz del impulso nacionalista (Martín Ezpeleta, 2008, 458).

No obstante, el mismo autor indica que, si bien las historias literarias han logrado que estos textos se conozcan y se lean "para satisfacer otras inquietudes de los estudiosos, resulta necesario reordenar y ampliar la información, el canon, desde otros presupuestos teóricos más ambiciosos y con contextualizaciones supranacionales" 
$(2008,459)$ como, en efecto, se ha realizado desde los años 70 del siglo $\mathrm{XX}^{4}$, período en el que la historiografía literaria comenzó a emplear como etiqueta alternativa la de "comedia nueva" en cuya elección pesaron criterios puramente literarios y contemporáneos a Lope. De esta forma, como ha señalado Rodríguez Cuadros (2002, 75), "tras la revisión del origen romántico e intuitivo del llamado teatro nacional, el término comedia nueva ha pasado a expresar una noción genérica para describir una formulación de síntesis de las prácticas escénicas que se desarrollan en la península desde el siglo XV al XVII". Parece importante, por tanto, revisar el uso de esta etiqueta en los libros de texto actuales, por cuanto nada concuerda con la sociedad de la que parten.

En el mismo manual observamos una constante que se repite en la mayor parte de los libros de texto analizados relacionada con la clasificación genérica de la obra calderoniana y, particularmente, con sus ausencias: entre su corpus se mencionan siempre los dramas de honor, los morales y filosóficos y los autos sacramentales, que pueden asociarse a temas morales, religiosos y filosóficos fundamentalmente. Y, solo de forma puntual y, por tanto, no en todos los libros, las comedias de enredo.

En primer lugar, debe considerarse que se trata de una clasificación genérica que mezcla criterios temáticos y estructurales y que ha sido revisada por la crítica. En este sentido es posible mencionar, en primer lugar, las investigaciones que se han llevado a cabo en el campo del género y recordar que cultivó obras dramáticas serias, integradas a su vez por tragedias, comedia seria (en donde se incluyen La vida es sueño o El alcalde de Zalamea) y auto sacramental; obras dramáticas cómicas, grupo del que forman parte la comedia de capa y espada, la comedia de figurón, las comedias palatinas, comedia burlesca y el entremés y otros géneros breves cómicos y obras cortesanas de gran espectáculo entre las que se incluyen, por ejemplo, las mitológicas (Arellano, 1995, 138-139). Dos, por tanto, son las facetas del teatro de Calderón que los manuales acostumbran a olvidar: el teatro cortesano y el teatro cómico, particularmente el breve.

En segundo ha de tenerse en cuenta, en relación con la elección genérica en la que predomina lo serio sobre lo cómico, cómo, en los últimos años, son varios los autores que han llamado la atención sobre la visión de Calderón como un autor serio y su identificación con los valores del honor, el catolicismo, la monarquía y el conservadurismo, principalmente como consecuencia de la influencia ejercida por el Romanticismo 5 .Tal y como ha apuntado Rodríguez-Gallego López $(2017,219)$, "el triunfo de este Calderón serio conllevó la progresiva relegación de su teatro cómico, con la única excepción de La dama duende", no por casualidad el único texto cómico que citan los manuales analizados. Muy interesante a este respecto es el trabajo de Mascarell $(2014,306)$ en el que, gracias a los resultados derivados de diferentes proyectos de investigación, ofrece dos listas de las obras calderonianas más representadas en el siglo XVII y de las más escenificadas entre 1939 y 1989 con resultados nada sorprendentes de acuerdo con lo aquí expuesto: en la primera lista las siete obras son cómicas; mientras que en la segunda solo una lo es, La dama duende, que ocupa el cuarto lugar precedida de La vida es sueño, El alcalde de Zalamea y El gran teatro

Recuérdese, por ejemplo, la monografía de Valbuena Briones del año 1977: Calderón y la comedia nueva. Iglesias Feijoo (2002, 2004, 2014), Pérez-Magallón (2010), Manrique Gómez y Pérez-Magallón (2006) y Rodríguez-Gallego (2017). De acuerdo con Manrique Gómez y Pérez-Magallón (2006, p. 431), la manipulación de Calderón para apoyar ideologías tradicionales y conservadoras proviene ya del siglo XVII y surge al hilo del debate en torno a lo nacional español. 
del mundo, los tres textos serios más citados en los manuales escolares que estamos examinando, lo que señala que dicho canon al menos proviene de 1939 y que se ha mantenido durante todo el siglo XX y parte del XXI.

Será, como hemos dicho, a principios del XIX cuando, en el contexto de la querella calderoniana, fundamentalmente a través de la figura de Böhl de Faber se presente a Calderón como estandarte de una manera concreta de pensar, reivindicando al autor como culmen de una España tradicional y conservadora. Dicha visión se afianzó de la mano de Menéndez Pelayo (Manrique Gómez y Pérez-Magallón, 2006, 432) quien logró que "el dramaturgo español quedara definitivamente convertido en icono característico de la visión conservadora de la identidad nacional española". Por ello, a partir de este momento, se seleccionó de su obra solo aquello que interesaba, olvidando o criticando otras formas de teatro creadas por Calderón que no recogían en modo alguno la ideología asociada al dramaturgo anteriormente expuesta. Así ocurrió, por ejemplo, con el teatro cómico o el teatro cortesano de tipo mitológico, que solo comenzaron a ser recuperados, por parte de la crítica, en la segunda mitad del siglo XX, puesto que antes, no apreciaron a Calderón "ni los del 98, ni los del 27" (Iglesias Feijoo, 2014, 140-141).

En relación con esta cuestión, resulta significativo prestar atención al manual de Vicens Vivens (Escribano Alemán y Rodríguez Delgado, 2016), que llama nuestra atención no por mencionar a Calderón sino por omitirlo en el contexto de un género, el de la comedia nueva, en el que Calderón destacó de forma particular. Así en el tema 11 al hablar de la comedia española y, concretamente de sus autores, se indica cómo "Lope de Vega (...) fue el máximo exponente de este tipo de comedia. Otros autores también importantes fueron: Juan Ruiz de Alarcón, Luis Vélez de Guevara y Tirso de Molina" (2016, 236). En el tema siguiente, el 12, sí encontramos referencia a Calderón, pero solamente a través de un fragmento de una adaptación de La vida es sueño que corresponde al monólogo de Segismundo. Al fragmento acompañan una serie de actividades que invitan a contrastar el texto calderoniano con un texto cómico breve de Lope de Rueda y que pretenden conducir al alumno a la conclusión de que el primer texto invita a reír al público y el segundo a reflexionar. Una vez más la imagen que se transmite de Calderón es la del dramaturgo serio y su faceta cómica queda olvidada.

Por último, y si atendemos a los seis libros de $3^{\circ}$ de la ESO, observaremos cómo en ellos se va un paso más allá de la teoría de los géneros literarios y los temas se concentran en el estudio de la historia de la literatura española a través de géneros concretos asociados a una época y obras específicas o fragmentos de ellas. En todos ellos encontramos varias líneas y, en ocasiones, apartados específicos dedicados a Calderón de la Barca, así como fragmentos de sus obras al hilo de los cuales se presentan distintas actividades (Romo Fernández, 2016, 252; Garrido González, 2015, 226; Jiménez Pérez, 2015, 128: González Bernal, 2016, 236; Pantoja Rivero et alii, 2015, 228, Arce et alii, 2015, 209). El análisis de estos libros constata la presencia del monólogo de Segismundo en todos ellos, aunque en cuatro casos a este acompañan fragmentos tomados de otras obras, lo que ayudará al alumno a ampliar su perspectiva sobre la obra del dramaturgo.

Si atendemos a la cuestión del corpus calderoniano y su clasificación genérica importa indicar cómo, de nuevo, en varios manuales (Romo Fernández, 2016; Garrido González, 2015; Arce et alii, 2015) se asocia la figura de Calderón con la composición únicamente de comedias de enredo, dramas filosóficos y de honor, entre los que se mencionan La vida es sueño y El alcalde de Zalamea, y de autos sacramentales. Solo dos amplían, con mayor o menor fortuna, esta clasificación. Por ejemplo, el 
manual de Oxford (González Bernal, 2016) resulta significativo por ser el único que ofrece una idea general del número de textos dramáticos de Calderón integrado por comedias, autos y piezas de teatro breve: 120 comedias, unos cien autos y decenas de piezas menores (236), además de añadir en una tabla general una clasificación de los textos dramáticos que no son autos sacramentales y que amplía en parte los presupuestos manejados hasta ahora. En dicho lugar se mencionan, con varios ejemplos en cada caso, las comedias de capa y espada (La dama duende y Casa con dos puertas mala es de guardar), los dramas de poderoso (El alcalde de Zalamea y La vida es sueño), las tragedias (El médico de su honra y El pintor de su deshonra), una etiqueta no localizada hasta el momento, y un último grupo titulado "Asuntos diversos" integrado, en realidad, por dos comedias que forman parte del grupo de las grandes comedias de espectáculo de tipo cortesano y mitológicas (El hijo del sol, Faetón y El monstruo de los jardines), una etiqueta que sí acuña, por ejemplo, el manual de MacGraw Hill (Pantoja Rivero et alii, 2015) de forma muy acertada. En este mismo contexto habrá que considerar la importancia que en la representación de estas comedias adquirió la rica escenografía que crearon los pintores italianos que llegaron a España para trabajar en las cortes de Felipe IV y Carlos II, un dato que de forma excepcional nos ofrece el manual de Edebé (Garrido González, 2015) pero que amplían algunos de los manuales del primer curso de Bachillerato que analizaremos después (Hernández y Cabrales, 2015; Bernabeu y Nicolás Vicioso, 2015).

Muy significativo resulta, por último, el manual de Edelvives (Jiménez Pérez, 2015), no solo por sus contenidos propiamente relacionados con el teatro áureo y con Calderón sino también por los vinculados con el género de la comedia nueva. $\mathrm{Ha}$ de mencionarse, a este respecto, el fragmento del guion de un episodio de $E l$ Ministerio del Tiempo, serie española que se ha emitido en los últimos años en TVE, que se reproduce al principio del tema dedicado al teatro barroco. Este corresponde a una escena interpretada por una de las protagonistas, Amelia Folch, quien asiste a unas clases sobre Lope de Vega en la Universidad de Barcelona en 1880, es decir, en el siglo XIX, al que antes nos hemos referido como responsable de haber asignado a la comedia áurea una serie de valores nacionales y etiquetas hoy modificadas de acuerdo con nuevos criterios. En dicho texto el profesor refleja a la perfección esta postura decimonónica sobre el teatro áureo frente a la actual, la que, precisamente, encarna Amelia Folch. Las actividades que siguen a este texto invitan a reflexionar de forma crítica a los alumnos sobre estas dos corrientes: la pasada y la presente. Sin duda, este fragmento y las interesantes consideraciones críticas que a propósito de él puedan hacerse chocan con el uso obsoleto en dos manuales de este curso (Garrido González, 2015 Pantoja Rivero et alii, 2015) de la etiqueta "comedia nacional" a la que antes nos hemos referido y que se repite, aún, en algunos libros del primer curso de Bachillerato que, a continuación, consideraremos (Mateos Donaire, 2015 y Hernández y Cabrales, 2015).

\section{Calderón ayer y hoy: del currículum al libro de texto del primer curso de Bachillerato}

Frente al ciclo anterior, el currículum señala, para el caso del primer curso de Bachillerato, un estudio específico de las obras más significativas de la literatura española mediante la lectura y análisis de fragmentos de estas. En los cinco manuales analiza- 
dos se observa una mayor profundidad y extensión en el tratamiento de la obra del autor madrileño; así se dedican apartados completos a títulos concretos, además de los dirigidos a ofrecer una clasificación general de su obra y, en todos los casos, se incorporan apartados biográficos más o menos extensos sobre el dramaturgo (Bernabeu Morón y Nicolás Vicioso, 2015, 299; Blecua, 2015, 360-361; Mateos Donaire et alii, 2015, 347-348; Romo Fernández, 2015, 327-328; Hernández y Cabrales, 2015, 314-316).

En lo que atañe a la clasificación de sus obras, de forma generalizada se observa referencia a los dramas de corte moral, las comedias de capa y espada y los autos sacramentales (Hernández y Cabrales, 2015; Romo Fernández, 2015; Mateos Donaire et alii, 2015; Blecua, 2015 y Bernabeu Morón y Nicolás Vicioso, 2015), aunque algunos añaden ciertas categorías como, por ejemplo, el drama católico (Hernández y Cabrales, 2015), etiqueta con la que se pretende hacer referencia a la comedia religiosa, a la que también aluden MacGraw Hill (Mateos Donaire et alii, 2015) y SM (Blecua, 2015); o el drama histórico-legendario, al que hace referencia el de Bruño (Bernabeu Morón y Nicolás Vicioso, 2015). Ambas denominaciones mezclan criterios temáticos y genéricos.

Un aspecto no mencionado hasta el momento, relacionado en parte con la cuestión genérica, es la importante relación que se establece entre música y teatro en el siglo XVII, un vínculo a partir del cual se cultivan en España por vez primera, precisamente gracias a Lope y Calderón, la ópera y la zarzuela. El manual de Santillana (Romo Fernández, 2015) dedica un bloque al final del capítulo sobre teatro barroco a esta cuestión. Para lo que aquí nos interesa, importa indicar cómo se ofrece información sobre el dramaturgo madrileño en tanto que creador del nuevo género de la zarzuela mediante la composición de sus obras El golfo de las sirenas y El laurel de Apolo, además de destacarse su composición de dos óperas (La púrpura de la rosa y Celos aun del aire matan) siguiendo la estela de Lope con La selva sin amor. Se trata de una línea de investigación muy destacada en los últimos años que, además del manual de Santillana, solo menciona de forma superficial el de MacGraw Hill (Mateos Donaire et alii, 2015).

En lo que se refiere a las obras concretas a las que se dedica un apartado exclusivo de nuevo predominan El alcalde de Zalamea (Hernández y Cabrales, 2015) y La vida es sueño (Romo Fernández, 2015; Mateos Donaire et alii, 2015; Bernabeu Morón y Nicolás Vicioso, 2015), esto es, las comedias serias; aunque el ejemplo de SM (Blecua, 2015) se ocupa, además, de El gran teatro del mundo y La dama duen$d e$, de forma que atiende prácticamente a todos los géneros cultivados por Calderón salvo el teatro cortesano.

Un panorama parecido es el que podemos trazar en cuanto a los fragmentos de textos: en cuatro casos (Bernabeu Morón y Nicolás Vicioso, 2015; Mateos Donaire et alii, 2015; Romo Fernández, 2015 y Blecua, 2015) los que se ofrecen para el análisis corresponden con el monólogo de Segismundo, aunque el de Santillana (Romo Fernández, 2015) presenta, además, un fragmento de El alcalde de Zalamea, obra que, de forma única, también escoge SGEL (Hernández y Cabrales, 2015). MacGraw Hill (Mateos Donaire, 2015) propone, también, un fragmento del auto El gran teatro del mundo y SM (Blecua, 2015), de forma excepcional, incluye, además del de La vida es sueño, un fragmento del auto El gran teatro del mundo y otro de la tragedia El médico de su honra, de forma que casi aporta el lector un ejemplo de cada uno 
de los géneros cultivados por el dramaturgo salvo del teatro cómico y del cortesano en paralelo a lo dicho sobre los apartados en el párrafo anterior.

Parece significativo retomar en este lugar la cuestión de las ediciones que se manejan para extraer los fragmentos de texto sobre los que trabajarán los alumnos a propósito de la cita, en el manual de SGEL (Hernández y Cabrales, 2015), de un fragmento de El médico de su honra. Se trata de un texto extraído de la edición de Aguilar, lo que indica que corresponde a la edición de los Dramas preparada por Astrana Marín en 1932. Son muchos los trabajos, no obstante, que han llamado la atención sobre cómo esta edición en ocasiones presenta textos taraceados, es decir, textos que mezclan dos versiones diferentes de la obra o bien lecturas que no pertenecen a Calderón sino a editores posteriores. En este caso concreto, tal y como ha explicado Armendáriz (2007, 269), el texto de Astrana Marín reproduce el de la edición de Hartzenbusch de 1848. Este tipo de problemas textuales se observan con claridad en el fragmento si uno lo coteja con el texto de la edición crítica de Cruickshank (1986, 173-175), lo que permite ver que en el fragmento del manual $(2015,324)$ hay lecturas erróneas. Una idea que se constata si examinamos también la edición posterior preparada por Armendáriz (2007). Resulta importante considerar las ediciones críticas modernas de los textos a la hora de citarlos, puesto que resuelven problemas textuales patentes en ediciones anteriores como la de Astrana Marín.

\section{Ilustraciones para acompañar el estudio de la obra de Calderón en los manuales del primer ciclo de la ESO y el primer curso de Bachillerato}

Finalmente, en lo que se refiere a las ilustraciones que acompañan y complementan los textos teóricos y literarios, conviene indicar que hemos localizado tres grupos diferentes.

Las primeras, que aparecen solo en los manuales de cursos más bajos, son aquellas vinculadas con el tema de la obra que se estudia o de sus personajes o personajes-tipo: así en el manual de Edelvives (Jiménez Pérez, 2015) de $1^{\circ}$ de la ESO (2015, 103), a propósito del monólogo de Segismundo, observamos la reproducción de una cadenas como las que mantienen al protagonista calderoniano prisionero en la torre; esta aparece también en otro de los manuales, el de Edebé (Garrido González, 2015) de $3^{\circ}$ de la $\operatorname{ESO}(2015,226)$, en el cual se identifica, asimismo, un niño vestido de Superman en relación con los escollos que los protagonistas de esta obra deben superar. Por último, encontramos la reproducción del personaje del espadachín (SGEL, $1^{\circ}$ BAC, Hernández y Cabrales, 2015, 315).

Otro grupo, particularmente significativo, está integrado por las ilustraciones relacionadas con el autor: como el retrato anónimo de Calderón del siglo XVII conservado en el Museo Lázaro Galdiano de Madrid que se reproduce hasta en cinco manuales de distintos cursos (Edebé $2^{\circ}$ ESO, Garrido González, 2016, 318; $3^{\circ}$ Edelvives, $3^{\circ}$ ESO, Jiménez Pérez, 2015, 128; MacGraw Hill, $3^{\circ}$ ESO, Pantoja Rivero et alii, 2015, 228; Editorial Teide, $3^{\circ} \mathrm{ESO}$, Arce et alii, 2015, 209; MacGraw Hill, $1^{\circ}$ BAC, Mateos Donaire et alii, 2015, 347); un retrato de Calderón sobre panel cerámico (Bruño, $1^{\circ}$ BAC, Bernabeu Morón Nicolás Vicioso, 2015, 299); una reproducción de la estatua de Calderón que preside la plaza de Santa Ana de Madrid (SM, $1^{\circ} \mathrm{BAC}$, Blecua, 2015, 360; Santillana, $1^{\circ}$ BAC, Romo Fernández, 2015, 327) y, por último, la reproducción del personaje completo como si de un dibujo animado se tratase 
(Edebé, $3^{\circ}$ ESO, Garrido González, 2015, 226). Merece la pena señalar cómo todas las ilustraciones que integran este grupo ofrecen al estudiante la idea de un Calderón serio y de avanzada edad, pues así se refleja el dramaturgo en las cuatro representaciones porque, en efecto, no se conocen cuadros que nos ofrezcan una imagen del dramaturgo a los veinte, treinta o cuarenta años. Tal y como ha explicado Iglesias Feijoo, "ese hombre serio, adusto, mal encarado, tenía que estar siempre meditabundo y reconcentrado, y como axioma se asumió que había de carecer de sentido del humor y, por tanto, sus obras no podían ser cómicas" $(2014,137)$.

En tercer lugar, encontramos un grupo de ilustraciones vinculadas con algún montaje significativo de alguna obra del dramaturgo, lo que permite explicar la dualidad texto-espectáculo. Por ejemplo el montaje de la Compañía Nacional de Teatro Clásico de La vida es sueño dirigido por Helena Pimenta en el que Blanca Portillo interpreta a Segismundo (Santillana, $3^{\circ}$ ESO, Romo Fernández, 2016, 252; SM, $1^{\circ}$ BAC, Blecua, 2015, 362; Santillana, $1^{\circ}$ BAC, Romo Fernández, 2015, 328) o El de la dama duende dirigido por Miguel Narros (SM, $1^{\circ}$ BAC, Blecua, 2015, 363).

Por último, y de forma aislada, en el apartado dedicado a Calderón del manual de Oxford Educación de $3^{\circ}$ de la ESO (González Bernal, 2016, 236) se localiza una ilustración del teatro de Palladio de Vicenza en el que se observa con claridad el principio de perspectiva que los escenógrafos italianos importaron al teatro español y, por supuesto, al de Calderón. No obstante, creemos que la imagen no concuerda de forma clara con el contenido.

\section{Conclusiones}

El panorama ofrecido permite observar cómo los manuales escolares del primer ciclo de la ESO y del primer curso de Bachillerato concretan los contenidos ofrecidos por el currículum correspondiente y, asimismo, cómo estos son reflejo o no de la sociedad que los produce en lo que se refiere a valores, actitudes, estereotipos o ideologías.

En primer lugar, conviene indicar cómo Calderón de la Barca se trata como contenido solo a partir de los manuales de segundo de la ESO aunque desde los de primero encontramos fragmentos literarios de su autoría.

Merece la pena llamar la atención sobre la idea de que, salvo excepciones, la visión que se ofrece del dramaturgo en los manuales de Lengua castellana y Literatura de Secundaria es la de un autor apegado a valores como honor, el catolicismo, la monarquía y el conservadurismo, una perspectiva que proviene, como se ha explicado, del siglo XIX, época en la que se fraguó la etiqueta de "comedia nacional" para designar la denominada y concebida por Lope "comedia nueva". Ni la etiqueta que se asigna a su teatro ni la percepción de Calderón como dramaturgo serio, bien reflejado en algunas de las ilustraciones que se han localizado en los manuales, tiene que ver con la percepción que se tenía de la obra del dramaturgo en los siglos XVII o en la actualidad. Esta idea puede constatarse al revisar la alusión que encontramos en estos manuales a algunos de los subgéneros en los que se divide su obra y los textos que los ejemplifican, pero también si prestamos atención a la omisión de otros subgéneros y obras concretas. A este respecto, debe recordarse la identificación de Calderón fundamentalmente como autor de dramas de honor, filosóficos, religiosos y autos sacramentales con los temas, personajes y obras que pueden aso- 
ciarse a estos géneros. Tampoco en este último sentido se observa una perspectiva amplia en los manuales revisados y, así, del corpus calderoniano compuesto por más de ciento veinte comedias comedias y cien autos, los textos más citados son fragmentos procedentes de La vida es sueño, a la que siguen con cierta distancia $E l$ alcalde de Zalamea, El médico de su honra o El gran teatro del mundo, todas ellas obras serias. Si encontramos un desajuste en cuanto a subgéneros y obras entre los manuales y la crítica calderoniana actual, también lo hacemos en lo que se refiere a los tipos de ediciones que se escogen para las citas de los distintos fragmentos. Uno de los problemas fundamentales del campo de los estudios auriseculares hace aproximadamente treinta años era la falta de ediciones críticas fiables de las obras de todos los dramaturgos del siglo XVII sobre la cual construir las investigaciones. Por tal motivo, "la mayor parte de los estudios se basaban en textos dudosos, a veces mendaces, siempre inseguros" (Iglesias Feijoo, 2014, 143). Este trabajo se ha ido llevando a cabo de forma paciente y de la mano de distintos grupos de investigación y generaciones hasta la fecha, lo que ha contribuido a solventar en gran medida esta dificultad (Iglesias Feijoo, 2014, 142). Por esta razón sería deseable que los fragmentos citados en estos manuales, por breves que fueran, se reprodujeran a partir de ediciones fiables, sean estas escolares o no, como, en efecto, hace alguno de los manuales revisados.

A pesar de lo apuntado hasta aquí, resulta significativo señalar asimismo cómo algunos manuales, aunque sea de forma excepcional, ofrecen una perspectiva más amplia de la obra de Calderón y más cercana, también, a los presupuestos de la historiografía literaria moderna. Esta incluye, como contenido, bien su teatro cómico, en forma de comedia, habitualmente de capa y espada, o teatro breve; bien su teatro cortesano, del cual se estudia la importancia de la escenografía o la relación con la música, vínculo que generó los primeros ejemplos de ópera y zarzuela en España. Además se ha visto cómo al menos en uno de los manuales se reflexiona, a través de un recurso didáctico audiovisual, sobre el pasado y el presente de la recepción de la comedia nueva, contexto en el que triunfó Calderón en el siglo XVII como autor polifacético y versátil pero, de forma significativa, en tanto que dramaturgo cómico.

\section{Bibliografía}

Arellano Ayuso, Ignacio (1995): Historia del teatro español del siglo XVII, Madrid, Cátedra. Armendáriz, Ana (ed.) (2007): Pedro Calderón de la Barca, Edición crítica de El médico de su honra de Calderón de la Barca y recepción crítica del drama, Pamplona / Frankfurt, Universidad de Navarra / Iberoamericana.

Astrana Marín, Luis (ed.) (1932): Obras completas, Madrid, Aguilar.

Ayala Ato, Serafín y A. Montaner Bueno (2017): "Revisión del tratamiento de las normas ortográficas de las grafías "g” y “j” en manuales de segundo y tercer ciclo de Educación Primaria y sus repercusiones en la enseñanza, en Contextos educativos: Revista de educación, 2, 83-101, doi: http://dx.doi.org/10.18172/con.2909

Arboleda González, Diana (2017): "Ficha de análisis especializada para manuales de aprendizaje de español como segunda lengua", en Tonos digital: Revista electrónica de estudios filológicos, 33 . 
Cienfuegos Antelo, Gema (2016): "La educación literaria y el teatro del Siglo de Oro en Primaria: el proyecto comedia-va", en Multiarea. Revista de didáctica, 8, 147-170, doi: http://dx.doi.org/10.18239/mard.v0i8.1150

Cruickshank, Don (ed.) (1986): Pedro Calderón de la Barca, El médico de su honra, Madrid, Castalia.

Escolano, Agustín (2009): "El manual escolar y la cultura profesional de los docentes", en Tendencias pedagógicas, 14, 169-179, doi: 10.15366/tp

González Felipe, María Esther et alii (2017): Estudio del tratamiento del enlace químico en los libros de texto españoles, en REDIE: Revista Electrónica de Investigación Educativa, 19, 3, 60-70, doi: https://doi.org/10.24320/redie.2017.19.3.1184

Hartzenbusch, Juan Eugenio (ed.) (1848-1850): Comedias de don Pedro Calderón de la Barca, Madrid, Rivadeneyra (4 tomos).

Heredero de Pedro, Carmen (dir.) (2013): Otras miradas, Aportaciones de las mujeres a la lengua y literatura castellanas para integrar en el currículum de Secundaria, Madrid, Ministerio de Sanidad, Servicios Sociales e Igualdad.

Iglesias Feijoo, Luis (2002): “Calderón y el humor”, en Ayer y hoy de Calderón. Actas seleccionadas del Congreso Internacional celebrado en Ottawa del 4 al 8 de octubre del 2000, Ruano de la Haza, J. M. y J. Pérez Magallón (eds.), Madrid, Castalia, 15-36.

Iglesias Feijoo, Luis (2004): “Calderón, ayer y hoy. Sobre el origen romántico de la visión actual de Calderón”, en Proyección y significados del teatro clásico español. Homenaje a Alfredo Hermenegildo y Francisco Ruiz Ramón, Díez Borque, J. M. y J. Alcalá-Zamora (eds.), Madrid, Sociedad Estatal para la Acción Cultural Exterior, 2004, 139-159.

Iglesias Feijoo, Luis (2014): “La renovación de Calderón”, en Cuadernos de Teatro Clásico, 29, 135-152.

López García, María (2006): La variedad geográfica del español en el género "manual escolar", Lectura y vida: Revista latinoamericana de lectura, vol. 27, n 1, pp. 42-51.

Manrique Gómez, Marta y J. Pérez-Magallón (2006): “Menéndez Pelayo y la apropiación conservadora de Calderón como icono de la identidad nacional", Boletín de la Biblioteca de Menéndez Pelayo, 82, 429-445.

Martín Ezpeleta, Antonio (2008): "El concepto de nación en la historiografía literaria española", Literatura y nación: la emergencia de las literaturas nacionales, Leonardo Romero Tobar (ed.), Zaragoza, Prensas Universitarias, 433-466.

Martín Martín, Carmen (2002): “Criterios para el análisis de libros de texto desde la perspectiva de la Didáctica de la Matemática: Aplicación a la estadística y probabilidad, en Aportaciones de la didáctica de la matemática a diferentes perfiles profesionales", Penalva Martínez, M. del C., G. Torregrosa Gironés, J. Valls González (coord.), Alicante, Universidad, 373-385.

Mascarell, Purificació (2013): "El canon escénico del teatro clásico español: del siglo XVII al XX", en Teatro de palabras, 7, 305-317.

Ontanaya Pastrana, Miguel Ángel (2004): "El teatro del Siglo de Oro en la educación secundaria obligatoria y el bachillerato", en Textos de didáctica de la lengua y la literatura, 37, 111-121.

Palacio González, Sergio (2017): Los textos literarios clásicos en la enseñanza-aprendizaje del español como lengua extranjera (LE): Estudio, corpus, propuesta didáctica y puesta en práctica para los niveles A1-A2, Tesis doctoral dirigida por Isabel Santos Gargallo (dir. tes.), Pablo Jauralde Pou (dir. tes.), Dolores Noguera Guirao (tut. tes.). Universidad Autónoma de Madrid.

Pérez Fernández, Julián Jesús (2009): La motivación en la Educación Secundaria Obligatoria: estudio y tratamiento interdisciplinar a partir de una obra teatral española del Siglo 
de Oro, Tesis doctoral dirigida por Alfredo Rodríguez López-Vázquez (dir. tes.). Universidade da Coruña.

Pérez Fernández, Julián Jesús (2011): Motivar en Secundaria. El teatro: una herramienta eficaz, Barcelona, Erasmus Ediciones.

Pérez-Magallón, Jesús (2010): Calderón, icono cultural e identitario del conservadurismo político, Madrid, Cátedra.

Real Decreto 1105/2014, de 26 de diciembre, por el que se establece el currículo básico de la Educación Secundaria Obligatoria y del Bachillerato, Boletín Oficial del Estado, sábado 3 de enero de 2015.

Rodríguez Cuadros, Evangelina (2002): “Comedia nueva", en Diccionario de la comedia del Siglo de Oro, Frank P. Casa, F., L. García Lorenzo y G. Vega García-Luengos (dirs.), Madrid, Castalia, 75-78.

Rodríguez- Gallego, Fernando (2017): "La tentación de los serio: a propósito de El astrólogo fingido, Anuario Calderoniano, 10, 219-236.

Sáinz García, Ángel María (dir.) (2014): Arriba el telón: enseñar teatro y enseñar desde el teatro. Propuestas didáctica para trabajar el teatro en clase de español, Madrid, Ministerio de Educación, Cultura y Deporte.

Sánchez Dueñas, Blas (2012): "La perspectiva de género en la enseñanza de la literatura aurisecular, en Didáctica. Lengua y Literatura, 2012, 24, 411-431.

San Martín Alonso, Ángel y J. Peirats Chacón (2017): "Repensando la labor pedagógica en la escuela. Del libro de texto a los textos sin libros", en Telos: Cuadernos de comunicación e innovación, 106, 39-46.

Udaondo Alegre, Juan (2008): Didáctica del teatro histórico del siglo de oro español: una aproximación hermenéutica, Tesis doctoral dirigida por Alfredo Rodríguez López-Vázquez (dir. tes.). Universidade da Coruña.

Vara López, Alicia y Z. Vila Carneiro (2016): "Segismundo y su torre: la literatura áurea como recurso para el tratamiento de la integración en el aula de Educación Infantil", en Tejuelo, 24, 161-188, doi: 10.17398/1988-8430.25.161.

Vila Carneiro, Zaida (2017): "Hacia una didáctica de la literatura áurea en el siglo XXI", en Lenguaje y Textos, 46, 89-102, doi: https://doi.org/10.4995/lyt.2017.7455

Vila Carneiro, Zaida (2015), "Literature in SFL situations: Some ideas for teaching Spanish Golden Age theatre", en Docencia e investigación, 25(2), 11-25.

\section{Corpus de libros de texto}

\section{$1^{\circ}$ ESO}

Arce, Mercè et alii (2015): Lengua castellana y Literatura, $1^{\circ}$ ESO, Barcelona, Editorial Teide.

Garrido González, Antonio (dir.) (2015): Lengua y Literatura, $1^{\circ}$ ESO, Barcelona, Edebé.

González Bernal, José Manuel (2015): Lengua castellana y Literatura, $1^{\circ}$ ESO, Madrid, Oxford Educación.

Gutiérrez, Salvador et alii (2015): Lengua y Literatura, $1^{\circ}$ Educación Secundaria, Madrid, Santillana.

Jiménez Pérez, Elena (coord.) (2015): Literatura, ESO 1º Barcelona, Edelvives.

Pantoja Rivero, Juan Carlos et alii (2015): Lengua castellana y Literatura, $1^{\circ}$ ESO, Madrid, MacGrawHill Education. 


\section{$2^{\circ}$ ESO}

Escribano Alemán, Elena y P. Rodríguez Delgado (2016): Lengua Castellana y Literatura, 2.3, Barcelona, Vicens Vivens.

Garrido González, Antonio (dir.) (2016): Lengua y literatura, $2^{\circ}$ ESO, Barcelona, Edebé.

González Bernal, José Manuel et alii (2016): Lengua castellana y literatura, $2^{\circ}$ ESO, Madrid, Oxford Educación.

Gutiérrez, Salvador et alii (2016): Lengua y literatura $2^{\circ}$ ESO, Madrid, Anaya.

Hinojal, Jesús (dir.) (2016): Lengua y literatura, ESO 2ª Madrid, Bruño.

Moreno, Pedro et alii (2016): Lengua castellana y literatura $2^{\circ}$ ESO, Barcelona, Casals.

Romo Fernández, Leonor (dir.) (2016): Lengua y Literatura, $2^{\circ}$ ESO, Madrid, Santillana.

\section{$3^{\circ} \mathrm{ESO}$}

Arce, Mercè et alii (2015): Lengua castellana y Literatura, $3^{\circ}$ ESO, Barcelona, Editorial Teide.

Garrido González, Antonio (dir.) (2015): Lengua y Literatura, Bloque II: Literatura, Barcelona, Edebé.

González Bernal, José Manuel (2016): Lengua castellana y Literatura, $3^{\circ}$ ESO, Madrid, Oxford Educación.

Jiménez Pérez, Elena (coord.) (2015): Literatura, ESO 3, Barcelona, Edelvives.

Pantoja Rivero, Juan Carlos et alii (2015): Lengua castellana y Literatura, $3^{\circ}$ ESO, Madrid, MacgrawHill.

Romo Fernández, Leonor (2016): Lengua y Literatura, $3^{\circ}$ ESO, Madrid, Santillana.

\section{$1^{\circ}$ BACHILLERATO}

Bernabeu Morón, Natalia y C. Nicolás Vicioso (2015): Lengua y Literatura, $1^{\circ}$ Bachillerato, Madrid, Bruño.

Blecua, José Manuel (coord.) (2015): Lengua castellana y literatura, $1^{\circ}$ bachillerato, Madrid, SM.

Hernández, Guillermo y J. M. CABrales (2015): Lengua castellana y Literatura, $1^{\circ}$ Bachillerato, Madrid, SGEL.

Mateos Donaire, Esperanza et alii (2015): Lengua castellana y literatura $1^{\circ}$ Bachillerato, Madrid, McGrawHill.

Romo Fernández, Leonor (dir.) (2015): Lengua y Literatura, $1^{\circ}$ Bachillerato, Madrid, Santillana. 